\title{
Human Resource Management Implementation at Startup Arena Corner
}

\author{
Farah Agharid Zahra', Tantri Yanuar Rahmat Syah ${ }^{2}$, Rhian Indradewa ${ }^{3}$, \\ Diana Fajarwati ${ }^{4}$ \\ ${ }^{1,2,3,4}$ Faculty of Business Economics, Esa Unggul University, West Jakarta, Indonesia.
}

Corresponding Author: Farah Agharid Zahra

\begin{abstract}
Arena Corner is a new startup engaged in applying sports venue rental related to everything that smells of sports. In an effort company's performance, it is necessary to implement good human resource management. The following purpose of this research is that research aims resource management (HRM) in the growth of Arena Corner startup. Considering Arena Corners of new digital startups are growing and require many human resources in the They need. Information systems so that the proper implementation of HRM correct maintain arena corner in the competitive digital startup competitive. The method applied uses human resources the approach with spectrum recruitment, personnel, people development, compensation benefit, and industrial relations. The results of this research show that the application of HRM becomes a necessity for startup companies. In winning competition, it is necessary to create a training center to print human resources that understand technology for the needs of the company and the needs of the startup ecosystem and can add income and new businesses in the era of startup the competition.
\end{abstract}

Keywords: Human resource management mission; Human resource management practices; HR startup, Arena Corner.

\section{INTRODUCTION}

Every year thousands of new startups emerge in the hope of success and become one of the businesses experiencing great success in a limited time (Akula, 2015; Jafari-Sadeghi et al., 2020a; JafariSadeghi et al., 2020b). This seems to an exact extraordinary when pure ideas have been presented that creates value in the economy. The problem begins when we look at statistics related to startup success and failure and find many startups that have failed and been forced to leave the competition arena. Despite emerging as a small business, startups create jobs and lead to innovation and competition. In their symbolic importance to economic growth, they bring benefits to their owners, employees, and investors because of their rapid growth. The startup growth model is different, and each startup has its growth model that is vulnerable to change over time (Nascimento, 2017).

From the beginning to the growth stage, these startups are inevitably faced with various challenges and obstacles. So, simple structure changes so that the need to specialize in operations will increase the importance of HRM's role in these circumstances (Blau, 1970). Therefore, the role of HRM for startups becomes more import critically more complex and must deliver good results to stakeholders. Here, the importance of a deeper focus on human resources as a prominent factor in gaining a competitive edge and distinguishing companies from each other is becoming increasingly apparent (Dana et al., 2016; Devine et al., 2019; Garousi et al., 2020), and companies that are aware of uncertainty will pay attention to human resources that are more productive than companies. When discussing human resources for startups, it 
means that the mission and practices of HRM appropriate should be designed to address the short and long-term needs of the company as well as how to try to meet them.

HRM in startups can have a variety of visions and missions where startup life depends on human resources (Nascimento, 2017). In addition, HRM practices should be more scientific and tailored to the needs of companies to increase the impact of individuals on startups (Mokhtarzadeh et al., 2018). Today, the biggest challenge facing startups is attracting and retaining top talent. start-ups compete with large organizations to attract and retain top talent. HRM practices can attract top talent and retain it in the best way to continue their activities. Therefore, challenges in startups include failures and obstacles in HRM practices such as startup weaknesses in various aspects of recruitment, incentive systems, performance assessments, et. In a competitive environment, HRM can add value to organizations.

Understanding the growth and success of startups can increase the motivation of a new generation to create startups (Jafari-Sadeghi, 2020). However, considerable attention is not paid to HRM on startups for a variety of reasons. This problem exists globally and can be seen in real terms within our country. Understanding employer and employee perspectives HRM's role in startup growth can help employers to take steps to align employee perspectives with the company's HRM mission and practices. On the other hand, the awareness of entrepreneurs' shortcomings in the company's HRM practices cannot be a way to strengthen HRM practices in the company.

Arena Corner is a web mobile-based application company developing, where the operational reach is in the DKI Jakarta area has the concept of leasing services for various sports venues. When high mobility conditions make sportsmen need an application that runs on all digital platforms, thus providing convenience to its users in helping to provide easy booking and get sports venues online and in real-time. Direct competitors today are still not many who start on digital platforms, so it has more value to consumers. Still, over time Arena Corner must create a strong strategy to stay afloat.

Human Resource Management Strategy is the best step to consider all factors related to human resources at arena corner startup because Human Resource Management is part of the process to manage the most valuable human resources assets and ensure everything necessary to meet the goals, suggestions, vision, and, mission of the company in the sphere of Human Resources Management.

Based on the explanation described above about the phenomenon of Human Resource Management in Arena Corner, human resource management variables become an important issue in winning the competition of digital startup business today that causes gaps. So that makes the background of researchers to conduct research entitled" "The Influence of Human Resource Management there is Business Arena Corner" (Case Study on Arena Corner Indonesia). This research aims to examine the role of HRM in the initial startup process up to the development process.

\section{LITERATURE REVIEW Human Resource Management}

The concept of Human Resource Management (HRM) was first developed in academic work in the United States and then increasingly applied (Mahdiraji et al., 2019a). HRM is a strategic, integrated, and comprehensive approach to the recruitment level development well-being of people working in the organization. It includes a set of policies designed based on management decisions to achieve the organization's desired goals (Mahdiraji et al., 2019). HRM practices companies must manage human resources to achieve optimal goals and sustain the enabled society. Assuming that the main purpose of any business is to increase profits or generate and deliver the 
desired services, HRM practices can be a strategic and efficient way to recruit employees who fit, motivate, and engage them, increase flexibility, and improve profitability (Mahmoud et al. 2019). Therefore, formulating HRM practices can be considered as managing people to achieve organizational goals and improve performance (Dana, 2017). HRM's practices include job design, recruitment and selection of employees, performance assessment, training and Development career planning, compensation, labor relations (Orakwue and Iguisi, 2020).

\section{Startup}

In recent years, it is been said that the definition of a startup should not to be based on the number of employees because there is no standard measure in this regard. Believe that the definition of a startup should focus more on revenue than the number of employees; although, these criteria can also depend on the type of industry. The researchers argue that it's easier to determine which companies aren't startups than to determine the opposite. As a case in, a reliable, repeatable, scalable, and proven business model that no longer requires venture capital should no longer be recognized as a startup (Blank, 2014). Ries (2012) defines startups as human entities created to provide new goods or services under extreme uncertainty.

Startups cover five stages of growth. In the first stage (existence), the main problem of the business is getting clients and delivering products/services. In the second stage (survival), the main problem is shifting the company from mere existence to a workable relationship between income and expenses. In the third (successful) phase, owners face the decision of exploiting the company's achievements and expanding or keeping the frying pan stable and detached. In the fourth stage (takeoff), the company is growing fast, and the biggest concern is financing. In the end, in the fifth stage (maturity of resources), the company consolidates, tries to find ways to maintain a competitive advantage, while at the same time focused on professionalizing the company and avoiding the ossification of innovation thinking (Nascimento, 2017; Sukumar et al., 2020). Each startup faces different challenges at different stages of its life cycle (Colombo and Piva, 2008), including financial challenges, human resources, support mechanisms, environmental elements (Salmanzadeh and Kawamorita, 2015). HRM comes as a solution to address emerging workforce challenges and business complexities once startups progress throughout the five stages of development (Nascimento, 2017).

Hornsby et al. (2005) consider job design, assigning tasks and objectives, training and development, employee relationships, working conditions, selection and hiring, incentive strategies, performance assessment as the most common HRM practices that affect employee motivation and satisfaction. They also form the theoretical framework of this research. The term "startup" has been widely used since the 1990s to describe young companies, tech companies, and small companies. Startups are usually recognized as small companies (with a relatively small number of employees) with a high growth rate that has recently rend market-related dated technologies (Robehmed, 2013), and due to the ease of establishment, they have attracted the attention of entrepreneurs to test their capabilities by building their businesses (Gering and Conner, 2002; Hajia et al., 2015; Jafari- Sadeghi et al. 2019).

\section{HRM Role in Startup}

HRM affects all aspects of the organization because IT supports employees who are the most important business assets. Therefore, employers need to be aware of HRM decisions from the beginning (Khan, 2017; Sadet et al., 2019a,b). (Nascimento, 2017) conducted a study on the role of HRM in startups through interviews with employees and entrepreneurs from the five startups. The results show that HRM can have several roles in growing startups - 
from strategic to non-strategic. In the study of HRM practice development in small and medium enterprises, Rojanapuwadol (2012) conducted a case study from the point of view of entrepreneurs and CEOs related to strategic human resources and labor relations. The results showed that small companies relied on different types of networks in recruitment (Mokhtarzadeh et al., 2020; Sadeghi and Biancone 2018). Although the companies in this study experienced instability in profits, they have been providing formula training since the formative years. With the problem of lack of financial resources, they emphasize psychological rewards rather than financial rewards. In addition, Baron and Hannan (2002) examined the extent to which HRM is important in the new economy. Some commentators have recently stated that the goal of building a managed company has been unprofitable. "Building to flip" has replaced "building to last" so that entrepreneurs and their financial backers are looking for a treasure trove of technology. The new economic turnaround represents the development of the organization as (at best) irrelevant or (at worst) a drag source of organizations in the world that assess on internet speed, a futile diversion of the time and energy of leaders from more important and immediate concerns that must be addressed.

Kunampurat and Nithila (2018) argue that retaining qualified employees in a labor-intensive, rigorous, and fast working environment is a great struggle for all industries, especially startup companies. When startups try to provide new products/services in the market, there are many challenges for their companies, such as problems in the face of competition, uncertainty about the future of the product, irregular income at an early stage, changes in tax policies, and regulated frameworks, high salaries paid by competitors and so on, all of which led to challenges in employee retention at startups. Therefore, there must be the right motivational strategy to retain employees. As a result of their study being assessed, a common problem facing almost all startups is their juggling workforce with various roles and responsibilities resulting from attribution. Furthermore, the presence of the best talent determines the success or failure of an organization to remain competitive in today's fast-changing world. Who is employed is not only important but how employees are managed and maintained is also considered important, as it says? Hiring and retaining a slain workforce is considered a major challenge for startup companies to be successful, and the reason for this is the organization's uncertain climate (Lee et al., 2017).

\section{MATERIALS \& METHODS}

In this study, qualitative research method was applied with study approach and application of HRM role in Arena Corner business. Qualitative research is often used to find complex properties of phenomena, which aim to describe and understand phenomena from researchers' point of view (Leedy and Ormrod, 2005). Qualitative research relates to the meaning of phenomena rather than measuring and evaluating them. Yin (2003) states that case studies do empirical investigations investigating contemporary phenomena in real-world contexts, especially when the boundaries between phenomena and contexts are unclear. Using case studies in this study is to provide possible analysis at startups, simultaneously analyze more than one unit, and increase confidence in results compared to single case studies (Pearce et al., 2014).

\section{RESULT AND DISCUSSION}

\section{Human Resource Management Planning.}

Human resource planning is a strategy or set of steps and approaches to manage or use human resources (HR) to achieve a goal/goals set by the company/ organization. Human Resources determine the human aspect of management positions related to obtaining, training, assessing, and compensating employees. This includes paying attention to their working 
relationships, health, safety, and justice issues. Special human resources are filled with programs concerned with people (employees) performed in the most effective organizational functions, facilitating people (employees) to achieve organizational and individual goals.

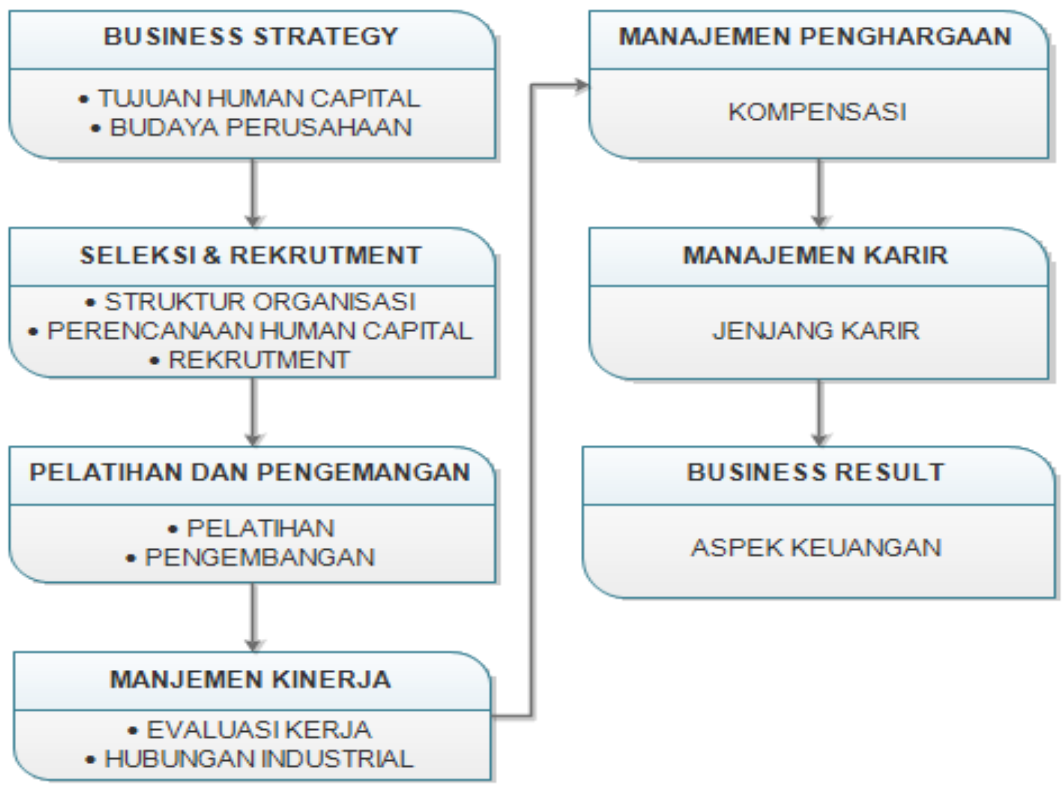

Figure 7.1 Human Resource Management Framework.

\section{Human Resources Management Objectives}

Arena Corner Company has a plan that do arranged in such a way and further managed well to take into account each side of each activity in the planned arrangement that aims to contribute development to maintain the company. The short-term goal is to get human resources that have high competence and integrity. The mediumTerm Objective is to Run a knowledge management program to improve employees' ability following the needs of Arena Corner and conduct a performance evaluation of human resources owned by Arena Corner. Long Term Goal to Increase the loyalty of human resources to remain loyal to work with Arena Corner, then Retain employees so that employees' expertise and knowledge are maintained.

\section{Human Resource Management Targets}

The target of human capital is a process run in the organization management system (in the application startup) designed and implemented is the wealth of human beings who perform excellent (high performing human assets). To ensure that it do achieved, the human resource function in the application startup must design measurement tools for each organizational management development system, especially in human beings that do implemented. Thus, an organization can ensure that the investment made by human resources related to knowledge, expertise, and behavior will ultimately increase confidence in oneself within the organization and the organization's success.

\section{Corporate Culture and Values}

Building a work culture is important for startup companies to create employee comfort in a work environment but still professional. Startups are synonymous with the relaxed work culture and not many rules. Human resource management plays a big role in ensuring that your startup can still create a quality work ethic while relaxed. Human resource management helps create a fun work environment that has a big impact on improving work productivity. 
Conducting refreshing activities for employees is one way to prevent employees from stress because they continue to struggle with work. Through these activities' employees can also build a more solid kinship. Conflict of opinion tends to be found more often at startups. If that happens, human resource management plays an intermediary role in disputes to maintain a friendly and professional work atmosphere.

PT. Arena Corner Indonesia focuses on developing mobile-based application applications. First time PT. Arena Corner builds a company with an organizational culture that we do so far: Creativity, thinking outside the shell, or "Out of the Box" we use imagination and insight to provide more value for stakeholders. Team, qualified personnel in their fields, loyal and dedicated to the company, able to build a system that can develop talents and potential human resources (HR) owned by the company and play a maximum role for the progress and welfare of the Joint. Passion, the spirit of the soul to devote themselves to the task completely, overcome new challenges, improve self-quality, and improve performance (teamwork). Innovation, the spirit of thinking more advanced to always look for something new, to a better goal. In terms of processes, methodologies, systems, and viewpoints

\section{Company logo}

The company logo is based on the company's philosophy and signifies the company itself. Why do we choose blue, orange and red? Exposure to short wavy colors such as blue and green gives rise to a feeling of calm in exercising; on the contrary, red and yellow stimulate the desire to exercise more actively. And a sign like a picture in the middle of hoping PT. Arena Corner Indonesia is a company that develops in the field of information technology and shines.

\section{Company uniform}

Standard arena corner dress set by the company is sporty where the company's uniform will describe the company so that employees all levels wear the same uniform, while for others will know and see that the identity of the arena corner company will increase the motivation of work for employees. Here is the uniform shape of the arena corner, as shown in the following image.

\section{Company Value}

PT. Arena Corner Indonesia has corporate values: Placing Consumers as the highest priority in all aspects of our business. The basic value must be real and felt in consumers' activities to safely and comfortably use the arena corner application.

\section{Assumption}

Competition between companies in the era of globalization is getting sharper, so human resources are required must able to develop themselves proactively. Human resources must want to be human beings who want to learn and work hard vigorously so that the human potential grows to the maximum because HR is a resource that is mean organization. Human resources are resources that play an active role in the course of an organization and the decisionmaking process. So, it can be said that an organization does not mean anything in the absence of human resources. Human resources in the company need to manage professionally to realize the balance between the needs of employees and the demands and capabilities of the company's organization. That balance is the key for the company to grow productively and fairly. With professional management of human resources, employees do expect to work productively. Human resource management is called human resource management.

\section{Organizational Structure}

The company's organizational structure is useful to know the duties, responsibilities, and authorities of each 
work unit, and then each division must be competent in carrying out its duties and responsibilities. The following is the organizational structure of Arena Corner. Based on the organizational structure chart of Arena Corner, the responsibilities and authorities of each position can be described as follows:

\section{Human Resource Planning}

In the HR planning arena corner, there is department will plan HR needs up to five years by using a manpower plan, then will run the HRM process as follows.

\section{Employee Recruitment Online Recruitment}

There is no denying that several companies currently do online recruitment to get the desired workforce. Many media professionals such as LinkedIn, Jobstreet, and JobsDB provide information and even labor recommendations that match the company's values if using the premium services provided. Companies only need to manage information and profile pages, sort applicants and summon potential candidates to the company for further proceedings.

\section{University Recruitment}

IT-based universities are developing in Indonesia, and the company believes that universities are an ideal place to find potential candidates to work in the company. The recruitment has done by working with career divisions with general requirements such as IT projects, portfolios, and experience in the digital field. The selection of universities is chosen based on the credibility and quality of campus graduates recognized by the community.

\section{Recommendation}

In addition to utilizing recruitment through Online media and universities, the company is also considering recruiting workers through recommendations from both employees who have worked in the company and related parties to the company. But with this recommendation system does not allow the candidate to get special treatment and follow hiring procedures like other candidates.

\section{Hackathon Contest}

In the startup world, it is very common for technology companies to find talented seeds in the world of technology. The company is also considering holding a competition as a process of finding the best employees.

\section{Selection System}

The selection system has a process to find the right person for the position the company needs, which is treated by prospective employees who pass the selection process. In general, the process phase does carry out as follows: first administrative selection. Both basic are ability tests - third Interview. The four activities on the job training three 3 , months and the fifth are signing the contract to be an employee. Before choosing a qualified employee for the company, the company must also be smart to choose who can carry out these responsibilities well. Recruitment methods that the company can choose in cod recruitment such: web companies, advertising Kalibrr, Jobstreet, and email the human resource management team should be able to identify the recruitment needs of each division and know the quality that the company appreciates from each candidate. Teams must also be selective in selecting candidates. Not necessarily someone with senior experience in a large company has what the company needs. In addition, the human resources management team must also know what can encourage employees' morale and help overcome the problems that arise. Employees who are accepted will be included in the On-the-Job Training (OJT) activities for three months to see the ability and performance of the employee. If the employee is declared graduated in the Onthe-Job Training (OJT) activities, the employee will be appointing as a permanent employee of the company. 


\section{Learning and Development}

Learning and Development aim to improve the performance of each employee both in groups and individuals, with this learning will improve the skills and knowledge for all employees in a company to be part of the management strategy to align the design of goals with the entire vision of the company's existing target mission.

\section{Coach}

Trainers or instructors do conduct by companies that are pro-training education actions to employees. Trainers provide an important into the progress of the capabilities of the employees to be develops. Coaches who will develop people development are internal, external, and internal and external coaches. First is the Internal Coach. The internal coach is an arrangement or a team of coaches assigned from the company to provide training or education to employees. Each head of the section is an internal trainer for his subordinate employees by providing instructions to get the job done and using tools, machines, and others. The nature of development given by the direct supervisor is continuous as long as the employee becomes his subordinate. The development carried out by a team by a coach is only temporary as long as the training or education is carried out. Internal trainers only train employees in the company environment. The second is External Coach. A person and team of trainers from outside the company must provide development to employees, whether the coach does bring in or his employees are assigned to attend educational institutions or training. The third is Internal and External Joint Training. Internal and external joint training is a combined team of internal and external trainers that provide development to employees. This method is best because the trainers will fill each other in providing development to employees.

\section{Training and Certification}

Employee development improves the technical, theoretical, conceptual, and moral skills of employees through training and certification. Training and certification must be following the needs of the current and future work. Training is an activity designed to give students the knowledge and skills needed for their current work (Eriyanto et al., 2021). Development is learning beyond the current work and has a long-term focus (Eriyanto et al., 2021) Human resource development is a follow-up step of the labor provision process that aims to ensure and maintain the available workforce to meet the required qualifications and be able to perform work in line with the company's strategic planning and achieve the company's objectives as planned.

\section{Compensation System}

Compensation is the entire repayment received by employees due to the implementation of work in the organization in the form of money or other. In short, compensation has two dimensions. The first dimension is the factor related to money (direct), and the second is not related to money (indirect) (Imron et al., 2020). This compensation relates to money in salaries, wages, bonuses, incentives, and other benefits such as health benefits, holiday allowances, meals, leave money, and others. Direct compensation in the form of wages or salaries, bonuses, and commissions, while indirect compensation such as efforts to improve the calmness and satisfaction of employees such as benefits. Several factors affect compensation, namely education, experience, dependents, company capabilities, economic conditions, and employment conditions. The purpose of compensation and payroll is to create loyalty and retention of employees, especially non-permanent employees who easily change jobs. Arena Corner will provide compensation and payroll following employee Key Performance Indicators (KPIs) to increase work motivation and 
minimize employee turnover. The rewards are financial and non-financial.

\section{Job Evaluation}

Arena Corner conducts performance assessments every six months to determine salary increases or incentives each year. Performance assessment is useful for setting policies that the company will take. Assessment needs to carefully and thoroughly so that employees do their job well to provide satisfaction for patients who receive health services. The aspects assessed are knowledge of his work, leadership, initiative, quality of work, cooperation, decision making, creativity, reliability, planning, communication, intelligence, problem-solving, delegation, attitude, effort, motivation, and organization. It is group into technical, conceptual, and interpersonal relationships.

\section{Termination of Employment}

Termination of Employment is something that in the past few years is an activity feared by employees who are still actively working. Due to the faltering political life conditions, followed by the collapse of economic conditions that affect many industries that have to go out of business, termination of employment done very unplanned. Termination of employment or layoffs is the termination of employment due to a certain thing that results in the expiration of the rights and obligations of workers or workers and employers (Law no. 13 of 2003 on Employment, article 1 paragraph 25). There are two kinds of terminations or layoffs, namely temporary layoffs and permanent layoffs. Temporary layoffs are two types, namely while not working for reasons such as family problems, health, continuing education, and others; temporary dismissal for economic and business reasons of the company. Permanent layoffs consist of three types of atresia or permanent dismissal due to resigning, retirement and death; termination; or death.

\section{Retirement}

In doing employee pension, there are several things of concern to the company, such as the age of the employee where it is necessary to take into account the age of the employee at the time of retirement, then the working period of the employee in the company, how long he worked as an employee at PT. Arena Corner. It is closely related to the reward to be awarded. The availability of company funds is also influential. The possibility of offering employees an early retirement plan can be consider, and lastly, the pension payment will be made once the employee retires at least five times the amount of the last home pay.

\section{Excommunication}

In carrying out the act of termination of employment, several things do consider by the company, among others: The first is the cause of the company's condition, it will do given the option to take early retirement for workers who have worked more than five years, or VP Human Resource can advise the CEO the names of employees following the quota that been determined. Employees affected by the termination of employment are given severance 1x THP and replacement money Rights. The second is because of personal conditions, such as If an employee does not enter work seven days in a row without notice and written evidence or a doctor's letter, Commits a serious violation according to company rules, Harms the company due to negligence of work, Detained for unlawful acts or social norms outside the company or using drugs, or Dismissal will do be done disrespectfully, and employees affected by the termination of employment will get severance following labor laws or employment agreements between the company and employees

\section{CONCLUSION}

The results showed that HRM practices applied by Arena Corner in order to be able to compete in the digital startup industry in Indonesia. Refers to the role of 
competent human resources in the limited startup world to anticipate employee piracy required to implement a strong and flexible HRM following the develop of the company and current conditions. Furthermore, this research shows that in Arena Corner, due to the small size of the company with many members, HRM Strategy has a strategic role in the company. However, HRM can have strategic or non-strategic missions. There is a specific framework for achieving multiple missions that follow digital companies' development and competitive conditions. Human resources with a strategic management style can be the key to business success in the new economic era (Gunawan et al., 2020) So the role of HRM is also very vital in the Startup Arena corner industry.

The limitation of this research is that there is no standard related to policy on startup companies, so competition is competing for potential human resources becomes very tight and sometimes has exceeded the limits of fairness. In this case, it becomes an interesting discussion by examining the impact of competition and meeting the needs of human resources on digital startups. As input to Arena Corner that it is necessary to implement strong People Development by increasing the training and competence of its workforce in order to compete with other companies, as well as creating a learning center to produce superior human resources in the field of technology so that they can meet the company's internal and external needs, so that can create more value and can become a new business unit.

Acknowledgement: None

\section{Conflict of Interest: None}

\section{Source of Funding: None}

\section{REFERENCES}

1. Akula, S. C. (2015). The Influence of Social Media Platforms for Startups. J. Mass Communicate Journalism, 5(264), 234-243.
2. Blank. (2014). Why companies are not startups.

Https://Steveblank.Com/2014/03/04/Why-

Companies-Are-Not-Startups.

https://steveblank.com/2014/03/04/why-

companies-are-not-startups.

3. Blau, P. M. (1970). A formal theory of differentiation in organizations. American sociological review.

4. Dana, L.-P., Grandinetti, R., \& Mason, M. C. .(2016). International entrepreneurship, export planning and export performance: evidence from a sample of winemaking SMEs. International Journal of Entrepreneurship and Small Business, 29(4), 602-609.

https://doi.org/https://doi.org/10.1504/IJES B.2016.079965

5. Dana, L.-P. (2017). International entrepreneurship research: how it evolved and directions for the future. International Journal of Entrepreneurship and Small Business, 30(4), 477-489.

6. Devine, R. A., Molina- Sieiro, G., Holmes Jr., R. M., \& Terjesen, S. A. (2019). Female- Led high- growth: Examining the role of human and financial resource management. Journal of Small Business Management, 57(1), 81-109.

7. Eriyanto, Y., Lestariani, R. I., Tantri Yanuar Rahmat, S., \& Indradewa, R. (2021). Human Capital Implementation Strategy in the Kamala Fertility Clinic. Journal of Multidisciplinary Academic ( ), 05(01), 8993.

8. Garousi Mokhtarzadeh, N., Amoozad Mahdiraji, H., Jafari-Sadeghi, V., Soltani, A., \& Abbasi Kamardi, A. (2020). (2020). A product-technology portfolio alignment approach for food industry: A multi-criteria decision making with z-numbers. British Food Journal., 76(1), 143-156. https://doi.org/https://doi.org/10.1108/BFJ02-2020-0115

9. Gunawan, R. I., Syah, T. Y. R., \& Fajarwati, D. (2020). Transformational Leadership Role in Human Resource Effectiveness. Journal of Multidisciplinary Academic, 4(6), 412-415.

10. Imron, H., Indradewa, R., Syah, T. Y. R. (2020). Compensation Effects and Organizational Climate on Employees' Performance by Organizational Commitment. Journal of Multidisciplinary Academic, 4(5), 300-307. 
11. Jafari-Sadeghi, V. (2020). The motivational factors of business venturing: Opportunity versus necessity? A gendered perspective on European countries. Journal of Business Research., 113(5), 279-289. https://doi.org/https://doi.org/10.1016/j.jbusr es.2019.09.058

12. Jafari-Sadeghi, V., Dutta, D. K., Ferraris, A., \& Del Giudice, M. (2020). Internationalisation business processes in an under-supported policy contexts: evidence from Italian SMEs. Business Process Management Journal, 45(3), 602-609. https://doi.org/https://doi.org/10.1108/BPMJ -03-2019-0141

13. Jafari-Sadeghi, V., Nkongolo-Bakenda, J.M., Dana, L.-P., Anderson, R. B., \& Biancone, P. P. (2020b). (2020). Home Country Institutional Context and Entrepreneurial Internationalization: The Significance of Human Capital Attributes. Journal of International Entrepreneurship., 3(1), 123-134. https://doi.org/https://doi.org/10.1007/s1084 3-019-00264-1

14. Kunampurat Paul, A., \& Nithila Vincent, T. (2018). Employee motivation and retention: issues and challenges in a startup,. International Journal of Creative Research Thoughts, 6(1), 2050-2056.

15. Lee, T. W., Hom, P., Eberly, M., Li, J. (2017). Managing employee retention and turnover with 21st-century ideas. Organizational Dynamics. http://www.sciencedirect.com/science/articl e/pii/S0090261617301833.

16. Mahdiraji, H. A., Kazimieras Zavadskas, E., Kazeminia, A., Abbasi Kamardi, A. (2019). Marketing strategies evaluation based on big data analysis: a CLUSTERING-MCDM approach. Economic Research-Ekonomska Istraživanja, 32(1), 2882-2892.

17. Mahdiraji, H. A., Mokhtarzadeh, N. G., Shateri, H., Beheshti, M. (2019). A Comparison Of Buyback, Rebate And Flexible Contracts In A Seller-Buyer Supply Chain. Transformations in Business \& Economics, 18(1), 1-11.

18. Mahmoudi, M., Mahdiraji, H. A., Jafarnejad, A., Safari, H. (2019). Dynamic prioritization of equipment and critical failure modes. Kybernetes, 48(9), 19131941.

19. Mokhtarzadeh, N. G., Mahdiraji, H. A., Beheshti, M., \& Zavadskas, E. K. (2018). A novel hybrid approach for technology selection in the information technology industry. Technologies, 6(1), 34. (Vol. 6, Issue 1).

20. Nascimento, C. (2017). What is the role of Human Resource Management in growing start-ups?

21. Orakwue, A., \& Iguisi, O. (2020). (2020). Conceptualizing entrepreneurship in human resource management. International Journal of Research in Business and Social Science, 9(3), 85-93.

22. Ries, E. (2012). Lean Startup: schnell, risikolos und erfolgreich Unternehmen gründen.

How to cite this article: Zahra FA, Syah TYR, Indradewa $\mathrm{R}$ et.al. Human resource management implementation at startup arena corner. International Journal of Research and Review. 2021; 8(8): 185-195. DOI: https://doi.org/10. 52403/ijrr.20210826 